\title{
EDUCAÇÃO DE ADOLESCENTES PRIVADOS DE LIBERDADE: UMA ABORDAGEM VIGOTSKIANA
}

\author{
Paulo Cesar Duarte Paes \\ Universidade Federal de Mato Grosso do Sul (UFMS), \\ Campo Grande, Mato Grosso do Sul, Brasil
}

\begin{abstract}
Resumo: Os adolescentes que cumprem medida socioeducativa de internação têm um histórico de pouquíssima frequência escolar, antes, durante e depois da internação. Utilizando a psicologia Histórico-Cultural de L. S. Vigotski, o artigo fundamenta uma concepção de que o psiquismo é histórico e não inato ou um ideal do espírito, pressupondo uma maior valorização de conteúdos científicos na educação escolar desses adolescentes. Na terceira parte fundamenta uma crítica à prática pedagógica que valoriza excessivamente o lúdico e que entende a autoridade e a disciplina como procedimentos pedagógicos autoritários e ineficazes. Conclui que a concentração e a disciplina para apropriação de conhecimentos ditos clássicos são fundamentais para o desenvolvimento dos adolescentes privados de liberdade.
\end{abstract}

Palavras-chave: Adolescente. Medida socioeducativa. Educação. Ensino.

A educação escolar para adolescentes que cumprem medida socioeducativa de internação deveria ser o primeiro direito e atividade essencial para aproximadamente 22 mil (SINASE, 2012) internos no Brasil. Além da falta do oferecimento da educação formal, a metodologia de ensino também afeta negativamente a escolarização desses adolescentes. Relatos demonstram que adolescentes ficam até três anos no sistema e continuam analfabetos, demonstrando o quanto o sistema é falho, devolvendo para a sociedade jovens ainda mais violentos e adeptos a práticas criminosas. 
Segundo levantamentos (SINASE/SDH-PR, 2012), a escolaridade de adolescentes que cumprem medidas socioeducativas de internação é muito menor do que a média nacional. Essa ausência de escolarização tem uma origem social nas políticas públicas notadamente as de educação e nas tradições familiares do adolescente que, por estarem excluídas econômica e culturalmente, em geral, não valorizam a escolarização ou não conseguem dar o devido apoio para os estudos dos filhos.

A educação formal não desenvolveu uma metodologia capaz de manter a criança e o/a adolescente na escola e, quando recebem a medida de Internação em Estabelecimento Educacional (ECA, art. 12), continuam sem estudar ou estudam muito pouco. Dentre as 450 unidades de internação no Brasil, muitas não tem sequer educação regular e uma parte delas ainda utiliza a EJA (Educação de Jovens e Adultos), que deveria servir para jovens trabalhadores que não tem tempo para estudar. No caso da internação a EJA representa uma perda de carga horária de estudo para quem mais precisa estar presente na escola.

Aproximadamente $60 \%$ das unidades de internação contam com escola de ensino regular, mas são raras as que garantem 20 horas aula por semana conforme preconiza a LDB (Lei de Diretrizes e Bases da Educação). Muitas unidades tornam facultativo ao adolescente o direito de estudar e muitos deles preferem ficar trancados nos alojamentos. Outras vezes fica difícil atender adolescentes de todos de variados anos implicando na diminuição radical de horas aula, quando o ideal seria que estivessem em período integral de 40 horas semanais.

A metodologia de ensino, em geral permissiva e focada no lúdico e no prazer temporário dos/as adolescentes, desvaloriza os conhecimentos científicos ditos escolares e hiper valoriza o senso comum, esvaziando o sentido da educação escolar. A sala de aula reproduz a lógica da cultura de massas, que tem um sentido lúdico de entretenimento, diferente da escola que necessita de autoridade, diretividade e disciplina para que sejam apropriadas as ciências, as formas mais complexas e abstratas da cultura, as eruditas e populares. A Psicologia Histórico-Cultural de L. S. Vigotski fundamenta uma crítica às práticas pedagógicas descritas acima.

Vigotski denunciou ostensiva e objetivamente aspectos inatistas de correntes da psicologia que compreendem o desenvolvimento da consciência como algo que advém do interior do indivíduo e não da história da humanidade. Essas mesmas tendências da psicologia produziram uma pedagogia que desvaloriza o conhecimento dito escolar. Segundo Vigotski (2001a, e 
2001b), as pedagogias idealistas negam a produção histórica do desenvolvimento, retirando do professor a autoridade advinda do seu conhecimento, inibindo o desenvolvimento do domínio da própria conduta inerente a vida social, o que pode contribuir indiretamente para a reprodução da violência pelos adolescentes.

A primeira parte do texto apresenta as principais reflexões de Vigotski acerca da historicidade do desenvolvimento do psiquismo e como a concepção ora inatista ora idealista prejudica o desenvolvimento dos adolescentes em geral (e em particular de adolescentes que cumprem medida socioeducativa de internação em estabelecimento educacional). A segunda parte demonstra como as psicologias inatistas e idealistas denunciadas por Vigotski contribuem para o foco da escolarização no lúdico, no senso comum, na cultura de massas e na desvalorização do conhecimento científico e estético, da autoridade do professor. Na educação de adolescentes que cumprem medidas socioeducativas, denominadas socioeducação, os conceitos científicos e a metodologia empregada para a apropriação desse tipo de conceito têm uma relevância ainda maior.

\section{VIGOTSKI, A HISTORICIDADE DO DESENVOLVIMENTO DO PSIQUISMO E A SOCIOEDUCAÇÃO}

A compreensão inequívoca de Vigotski acerca da origem histórica do psiquismo possibilita a quebra de uma série de mitos sobre o desenvolvimento e a aprendizagem dos adolescentes em geral e dos adolescentes autores de atos infracionais em particular. Dentre esses mitos destacam-se três: a identificação com o crime é inata; a aprendizagem somente acontece por meios lúdicos; a autoridade, a diretividade e a disciplina são procedimentos pedagógicos autoritários e ineficazes. Muitos são os textos de Vigotski (2004, 2001a, 2001b, 1996 e 1995) que abordam por variados ângulos a formação social e histórica da mente, o que muda radicalmente a metodologia de ensino a ser utilizada com os adolescentes e fundamenta a quebra dos mitos acima citados.

Vigotski desenvolveu sua teoria a partir de uma compreensão de unidade do entendimento psicológico, em que o meio sócio cultural, dado historicamente, é determinante, mas necessita de um corpo físico individual para desenvolver as funções psíquicas. Quando Vigotski critica a psicologia idealista, que percebe as funções psicológicas em si mesmas e desconectadas da vida material, refere-se ao aspecto que pode ser relacionado às forças 
materiais produzidas historicamente pela humanidade e, também, aos aspectos físicos biológicos do organismo humano, sobre os quais se efetivam as funções psíquicas:

É verdade que ela (a psicologia idealista) se justifica quando utiliza as palavras "fenômenos psíquicos"simplesmente para designar um grupo de fenômenos "sui gêneris" que diferem dos fenômenos ou objetos materiais porque eles, i.e., os fenômenos psíquicos, não existem no espaço sem ocuparem lugar, não são percebidos por olhos, ouvidos e demais órgãos dos sentidos e só são conhecidos imediatamente por quem os vivencia. Entretanto, acaso minhas idéias podem existir sem aquele lugar no espaço que se chama cérebro? Acaso não podeis ver ainda que parcialmente a minha alegria e ouvir os meus desejos? (VIGOTSKI, 2001b, p. 5).

Para ele, o instinto e os reflexos são parte do primeiro estágio do desenvolvimento do comportamento em todos os animais, sendo que nos seres humanos, esse traço passa por modificações mais profundas. Vigotski argumenta que, se por um lado existem mudanças fisiológicas que alteram os instintos e o funcionamento dos reflexos, por outro lado, essa alteração é inexpressiva se comparada às alterações proporcionadas pelas diferentes formas históricas de meios sociais que os indivíduos encontram prontas quando nascem.

Vigotski (2001a) afirma que a"velha psicologia"é incapaz de perceber os vários aspectos que se inter-relacionam resultando na unidade do psiquismo determinado historicamente. O meio social é um fator imprescindível para o desenvolvimento da experiência individual e do gênero humano e sem o qual não existiria o psiquismo.

O meio a que se refere Vigotski não é o meio estático da Fenomenologia' que percebe apenas as relações que acontecem dentro de um pequeno espaço social determinado pelas relações sensoriais do indivíduo. A gênese das relações desse pequeno grupo é muito mais ampla e em permanente estado de mudança. O indivíduo só é humano porque é histórico e se apropria ativamente da cultura como a particularidade de um gênero em permanente estado de transformação:

O homem usa a experiência das gerações passadas não só naquelas proporções que tal experiência está consolidada e é transmitida por herança física. Todos nós usamos na ciência, na cultura e na vida uma enorme quantidade de experiência que foi acumulada pelas gerações anteriores e não foi transmitida por herança física. Em outros termos, à diferença do animal o homem 
tem história, e essa experiência histórica, isso é, essa herança não física mas social difere-o do animal (VIGOTSKI, 2001b, p. 41-42).

Para Vigotski, a "velha psicologia" erra irremediavelmente porque entende unilateralmente os processos psíquicos como "naturais" e porque nega o caráter histórico do desenvolvimento psíquico, confundindo o natural com o cultural, e o biológico com o histórico e social. Tanto a tendência biologicista (inatista) quanto a espiritualista (idealista) da psicologia são criticadas por Vigotski (1995), por sua característica dualista, que ora contempla as "leis eternas da natureza", ora as "leis eternas do espírito" e não as "leis históricas", misturando numa só proposição teórica posições idealistas e biologicistas.

Importa saber qual a relação que estabelecem, de fato, as funções ditas inferiores de cunho biológico e as ditas superiores de cunho cultural, as inatas e as adquiridas, sem perder de vista a unidade que as condiciona no desenvolvimento humano.

Não existe dúvida que tanto um quanto outro tem sua importância, não só porque o desenvolvimento biológico da conduta, que se manifesta com particular intensidade após o nascimento, constitui por si mesmo um objeto de estudo psicológico, mas, também porque é impossível estudar a história do desenvolvimento das funções psicológicas superiores sem ter estudado a pré-história de tais funções, suas raízes biológicas e inclinações orgânicas (VYGOTSKI, 1995, p. 18).

Para aprofundar a compreensão sobre as características biológicas e naturais e como essas influem no desenvolvimento psíquico, Vigotski realizou, juntamente com seus colaboradores, ampla pesquisa sobre as condições físicas e o comportamento dos humanos primitivos. As pesquisas comprovaram suas hipóteses de que não existe diferença significativa no aspecto biológico entre os humanos primitivos e os mais cultos do mundo contemporâneo. Isso significa que não se pode atribuir à base biológica a imensa diferença que existe entre o comportamento dos seres humanos primitivos e os culturais:

Todas as investigações confirmam essa tese e demonstram a não existência de diferenças essenciais no tipo biológico do homem primitivo que possam condicionar as diferenças entre a conduta do homem primitivo e do homem culto. Todas as funções psíquicas e fisiológicas elementares - percepções, reações, movimentos, etc. - não mostram nenhuma diferença se a compararmos com as mesmas funções do homem culto (VYGOTSKI, 1995, p. 32). 
Além das pesquisas realizadas sob sua coordenação sobre o comportamento de seres humanos primitivos, Vigotski ${ }^{2}$ estudou vários autores que tratam do assunto, buscando compreender como se davam as funções psíquicas dos primitivos. Ele refuta como falsas todas as proposições que demonstram que as diferenças de comportamento entre os seres humanos primitivos e os culturais são calcadas em diferenças orgânicas. Para ele, as causas dessas diferenças são somente culturais e históricas.

Vygotsky ${ }^{3}$ e Lúria (1996, p. 104) afirmam que a aguçada acuidade dos sentidos do "homem primitivo", citada em ampla literatura sobre o assunto, como a visão, a audição e o olfato extremamente desenvolvidos, não tem sua causa na formação fisiológica, mas, na forma de vida dessas comunidades que necessitavam mais ou menos de determinados sentidos para sua sobrevivência e, em função disso, desenvolveram mais ou menos esses sentidos.

A memória dos seres primitivos é outra função bastante estudada por Vigotski, que contesta o fato de que eles não tinham uma memória bastante desenvolvida tendo em vista que sua forma de vida menos complexa do ponto de vista cultural não exigia essa função psíquica. $\mathrm{O}$ autor afirma a falsidade desta hipótese demonstrando que a vida nas comunidades primitivas exigia uma memória muito mais extensa, em termos quantitativos, do que um cidadão cultural do mundo contemporâneo pode supor. Nas comunidades primitivas a linguagem não atinge o mesmo desenvolvimento que na sociedade cultural, pois não existem conceitos generalizantes. Por exemplo: árvore designa todas as árvores, mas nas comunidades primitivas existe uma palavra diferente para designar cada árvore específica. Cada objeto ou criatura tinham que ser designados por seus próprios nomes, tornando necessário um número muito maior de palavras para que se conseguisse determinar verbalmente o sentido da comunicação (VYGOTSKY; LÚRIA, 1996, p. 121).

Na complexa linguagem da sociedade contemporânea a utilização de formas de classificação e generalização proporciona uma drástica redução do número de palavras necessárias para que se exerça a comunicação. A linguagem constitui-se em uma forma mais abstrata de generalizações, como um sistema de elementos muito sutilmente diferenciados. A comunicação moderna pressupõe a apropriação e a execução de uma atividade lingüística pelo sujeito, utilizando as palavras, não como simples reações concretas, mas como partículas de um complexo mecanismo conectado e combinado com outros elementos (VYGOTSKI, 1995).

A definição de "homem cultural" está associada a uma cultura mais complexa e avançada não apenas no aspecto quantitativo, mas principal- 
mente, no aspecto qualitativo. Vigotski (1995) afirma que todo o cultural é, por natureza, histórico e quanto mais a humanidade evolui no processo civilizatório mais a cultura torna-se complexa e qualitativamente superior. A cultura humana, nela incluída a linguagem, é mais que um meio externo de relações humanas, é um instrumento interno do psiquismo que sustenta a racionalidade e a emoção de cada indivíduo.

Vigotski utiliza a ideia de ferramentas que possibilitaram a ascensão humana para um grau de superioridade em relação aos outros animais. $O$ fato que proporcionou o início da produção da cultura foi exatamente o uso e a confecção de ferramentas de forma sistemática. Enquanto os animais sobrevivem do que a natureza lhes oferece, os seres humanos passaram a transformá-la através do uso de ferramentas. A atividade externa de transformação da natureza proporcionou, concomitantemente, a transformação interna.

Essa correlação entre o desenvolvimento cultural e biológico na história da humanidade (filogênese) e na história do indivíduo (ontogênese) evidencia uma diferença radical entre a Psicologia Histórico-Cultural e o que Vigotski chama de "velha psicologia". A velha psicologia parte do pressuposto de que o desenvolvimento das funções psicológicas superiores e as funções inferiores desenvolvem-se paralelamente na filogênese, o que dá margem a uma série de posições equivocadas. Embasada na perspectiva desse paralelismo a velha psicologia defende a tese de que as funções superiores têm sua gênese na individualidade e não no histórico e no social.

As formas superiores, definidas por Vigotski, são formas culturais mais complexas e evoluídas do desenvolvimento histórico que foram produzidas inicialmente como elementos simbólicos utilizados para orientar procedimentos e modos culturais de conduta. Uma quantidade de nós, dados numa corda por um primitivo, servia para lembrar algo. Um desenho, um gesto, uma forma qualquer elaborada a partir de algum material, que sirva como um signo abstrato, sem referência com o que tal objeto é de fato, é o início de novas formas culturais, mais complexas e abstratas, que produzem na história a complexa linguagem que identifica o ser humano como cultural.

Neste fato específico de introduzir meios artificiais e auxiliares na memorização, na criação ativa e o emprego de estímulos na qualidade de instrumentos da memória podemos ver, uma vez mais, o início de um comportamento novo e especificamente humano. O limite que separa a forma inferior da existência humana da superior é a aparição da linguagem escrita. O fato de 
fazer um nó como meio de recordação foi uma das formas mais primárias da linguagem escrita (VYGOTSKI, 1995, p. 77).

O processo único de apropriação das formas superiores pela mente está intrinsecamente relacionado ao desenvolvimento da cultura na história humana. As formas culturais de conduta desenvolvidas na individualidade são as formas culturais históricas, tendo em vista que o pensamento somente atinge graus superiores quando incorpora a cultura historicamente produzida. Essa cultura, reproduzida pelo pensamento que tem na linguagem o centro de sua existência, é um fundamento para que se compreenda o sentido e as possibilidades da prática de ensino e aprendizagem.

Os adolescentes que cometeram atos infracionais, que vivenciaram intensamente a violência social e que têm baixa escolaridade constituem-se num signo para a sociedade, que o compreende fora do seu contexto histórico, como algo à margem, maligno e repugnante, o "menor infrator". Quando o adolescente entra em contato com essa visão que "o outro" tem dele, constitui uma concepção de si mesmo, como um sujeito que pratica a violência e coloca-se à margem, "um menor infrator". Desde as formas de abandono, de negligência e de violência que o levaram, muitas vezes desde tenra infância, a reproduzir a violência social até o cumprimento da medida existem duas formas distintas que o influenciam: uma que percebe o adolescente em si mesmo e outra como síntese histórica de múltiplas determinações.

A negação da historicidade da reprodução da violência pelo adolescente cria uma barreira que inibe uma relação entre o professor e o/a adolescente. Desloca de uma possível relação construtiva e educativa para uma relação destrutiva e inibidora do desenvolvimento escolar do adolescente. $\mathrm{O}$ inatismo de forma mais radical, mas também o idealismo, denunciados por Vigotski são um fundamento, muitas vezes inconsciente, para que "o outro" continue compreendendo o adolescente como um ser inferior, "um menor infrator", acentuando o processo de destrutividade e inibindo o seu desenvolvimento. A compreensão do/a adolescente em si mesmo/a e não fruto de relações históricas impede a criação de um vínculo de confiança entre professor/a e adolescente prejudicando o processo de ensino e aprendizagem.

Se o psiquismo do indivíduo é histórico, remontando a ancestralidade da humanidade e o/a adolescente se apropriou dessas formas culturais, a violência não nasceu nele/a, não pode ser naturalizada, mas compreendida como algo que faz parte de um todo social e que o/a adolescente não deve e não pode ser punido pela sua conduta, mas impedido de continuar cometendo atos infracionais, responsabilizando-se pelos seus atos e educado ob- 
jetivamente. Não se trata de ser bonzinho com o/a adolescente e perdoá-lo/a, mas de compreender a gênese histórica da violência que o levou ao crime e agir objetivamente no sentido de mudar o seu psiquismo da condição de violência e destrutividade para uma relação de compreensão a aprendizagem.

Quando o autor soviético demonstra que não existem diferenças no aspecto físico entre humanos primitivos e culturais enfatiza a igualdade de condições de aprendizagem de um ou outro no seu aspecto biológico. As diferenças são culturais: a sociedade cultural utiliza linguagem e ciência mais complexas e generalizadoras, enquanto a primitiva usa uma linguagem mais simples onde cada objeto tem um referente. Não precisaríamos refazer essa pesquisa sobre as mesmas condições de desenvolvimento existentes entre um adolescente que cumpre medida socioeducativa e um adolescente de classe média que sempre estudou em boas escolas e tem todo o apoio da família. Do ponto de vista da constituição histórica do psiquismo eles são idênticos, o que os difere são as condições históricas de suas vidas.

Se os povos primitivos não tivessem aprendido a utilizar símbolos simples como os nós, as contas e outras ferramentas, hoje não teríamos toda a tecnologia, a ciência e as complexas linguagens que desenvolvemos. Os adolescentes internos tiveram negado o acesso a essas formas mais complexas da cultura, que não são apropriadas espontaneamente, mas somente pela mediação de um professor ou pessoa que domine a complexidade do objeto cultural e possua uma metodologia de ensino. Essa distinção pode ser compreendida quando o autor (VIGOTSKI, 2001b; 1995) define a diferença entre conceitos cotidianos e conceitos científicos. Os conceitos científicos são produtos da complexa cultura do nosso tempo, cujo acesso foi negado à grande maioria dos adolescentes que cumprem medida socioeducativa.

Esse entendimento muda radicalmente a metodologia de ensino voltada para esses adolescentes, objetivando reparar e restituir o desenvolvimento que lhes foi socialmente negado, proporcionando a internalização de limites em relação à violência e à destrutividade. Porém, as metodologias de ensino são também influenciadas por variadas concepções psicológicas, como o inatismo, o idealismo ou a psicologia histórico cultural e reproduzem entendimentos e práticas que podem ser mais ou menos eficientes no sentido de atingir o objetivo de educar o/a adolescente. Os métodos pedagógicos fundamentados nas psicologias inatistas e idealistas atrasam o acesso às formas culturais mais complexas (VIGOTSKI, 2001b). O ensino deve ser planejado de forma que a aprendizagem esteja além do estágio em que se encontra inicialmente o aluno, proporcionando o máximo desenvolvimento. Mas para 
isso é necessário valorizar os conhecimentos chamados de conteúdos escolares que, para serem apropriados, pressupõem concentração e disciplina.

\section{AUTORIDADE, DIRETIVIDADE E DISCIPLINA DA EDUCAÇÃO ESCOLAR DE ADOLESCENTES EM PRIVAÇÃO DE LIBERDADE}

O mito de que autoridade, diretividade e disciplina são procedimentos pedagógicos autoritários e ineficazes tem origem numa concepção psicológica em que o desenvolvimento acontece espontaneamente de dentro para fora do indivíduo. Na concepção histórico-cultural esses procedimentos são imprescindíveis para que os alunos se apropriem de conhecimentos científicos, estéticos e complexos, que não podem ser apropriados espontaneamente.

É necessidade que os conteúdos curriculares escolhidos pelos professores sejam clássicos, conforme a concepção de Saviani (2003). O professor deve saber distinguir entre um conteúdo acidental e um fundamental, entre $o$ principal e o secundário, entre o fundamental e o acessório, um conhecimento que permanece no decorrer da história.

As tendências pedagógicas, que não valorizam o conhecimento científico como centro do processo educativo ${ }^{4}$, contribuem para um relativismo de conteúdos onde qualquer forma de saber tem relevância no processo educativo, o que também contribui para que aquele adolescente que ficou três anos na unidade de internação continue analfabeto.

Falamos até agora de conteúdo curricular como um conhecimento distinto, não comum, científico. Se esses conhecimentos não se encontram na comunicação de massa e estão cada vez mais minguados nas tradições populares, onde estão? Temos duas respostas para essa questão. Claro que estão em toda parte (filmes, mídia, obras de arte, museus, comunidade etc.), pois tudo na cultura humana é conhecimento, mas existe um locus central do conhecimento científico, erudito e clássico: nos livros e na biblioteca. Os livros e a biblioteca são a materialização das culturas clássicas produzidas durante toda a história da humanidade. Quando o/a professor/a entende que adolescentes em privação de liberdade por cometimento de um crime grave, não precisam saber as ciências e as formas mais complexas da cultura, negam a eles uma possibilidade de desenvolvimento e a biblioteca perde o sentido como instrumento pedagógico. Para Vigotski a linguagem é ferramenta histórica que possibilita o pensamento e seu domínio é condição para o desenvolvimento. 
O professor, fundamentado no pensamento sócio-histórico, não aceita ser guiado por um livro didático. Ele vai estudar a fundo os conteúdos a serem ministrados em uma bibliografia diversificada. O domínio de cada conteúdo somente é possível através de estudos de várias fontes, possibilitando ao professor dar respostas, variadas em um amplo repertório, aos alunos que, percebem a qualidade do conhecimento do professor e tendem a imitá-lo. A imitação é o processo desencadeador de toda a aprendizagem e o professor deve saber pelo menos 100 vezes mais do que o conteúdo do livro que está ministrando (VIGOTSKI, 2001a).

Para Vigotski não existe prazer fácil na busca do conhecimento, mas um prazer que exige compromisso, dedicação e concentração e que deve ter no professor o seu maior exemplo. A educação histórico-cultural não está comprometida com o prazer imediato do aluno durante a aula, mas com seu prazer futuro no desenvolvimento de sua vida, mesmo que para isso o aluno tenha que desenvolver a capacidade de controlar os seus impulsos mais básicos e sofrer alguma forma de desconforto. Os conhecimentos sistematizados necessitam muito esforço para serem apropriados e, por isso, o professor não deve ter a função de manter os alunos em estado de felicidade, mas deixar claro que o processo educativo é difícil e, às vezes, penoso.

Toda aquela pedagogia que adocicava a "época dourada da infância serena" e o processo educativo com águas de rosas está fora do nosso caminho. [...] Por isso a educação deve ser orientada no sentido de não turvar e nem escamotear os traços cruéis do verdadeiro desconforto da infância, mas fazer a criança chocar-se de forma mais brusca e frequente com esse desconforto e levá-la a vencê-lo (VIGOTSKI, 2001a, p. 461-462).

A compreensão do aluno como um ser social e não como um indivíduo isolado é o que justifica a relevância do conhecimento sistematizado como central na educação escolar. Adolescentes internos não são apenas indivíduos que sofrem e se felicitam, mas uma parcela do gênero humano parte de uma comunidade que tem no conhecimento a única forma de romper com perversos ciclos de exploração humana e contribuir coletivamente para a produção de uma sociedade mais justa.

Para Vigotski (2001a), conteúdo e disciplina estão intimamente relacionados. Se o conhecimento é considerado o foco central do processo educativo então o entendimento sobre disciplina é mais rigoroso, para que se consiga apreender os conhecimentos mais complexos como as ciências ou as artes. O processo educativo escolar tem seu foco central no conheci- 
mento sistematizado e no ensino coletivo, por isso o rigor disciplinar é tão relevante. Se o sentido da aula é a aprendizagem do conhecimento histórico, o prazer do aluno deverá estar relacionado à apropriação significativa destes conhecimentos, mesmo que, para isso, o aluno sofra a pressão de toda a cultura histórica produzida em dezenas de milhares de anos e que deve ser apreendida em poucos dias (VIGOTSKI, 2001a).

Vigotski chega a falar da relação professor-aluno como um antagonismo hostil, como uma luta entre o interesse do professor em educar e a negação desse conhecimento pelo aluno. Um litígio entre as formas culturais e historicamente constituídas e os impulsos biológicos do aluno. Trata-se de uma verdadeira batalha travada na sala de aula e internamente nas consciências de ambos. Uma ação educativa histórica e não como o propalado por autores que compreendem a educação como algo natural e harmonioso:

A pedagogia diverge radicalmente da teoria da educação natural que vê o ideal no passado. Para Tolstói e Rousseau a criança é um ideal de harmonia e toda educação subseqüente apenas a estraga. [...] Uma criança recém nascida é um condensamento da experiência anterior, é pura biologia, e que em alguns anos do seu desenvolvimento ela deve superar efetivamente todo o caminho percorrido pela humanidade, do macaco ao aeroplano (VIGOTSKI, 2001a, p. 458).

A disciplina é apenas uma estratégia para que se atinja o objetivo da apropriação do conhecimento e deve ser parte de uma metodologia de ensino devidamente fundamentada e coerente com o objetivo central da educação escolar. Perder ou reduzir a capacidade de condução do ensino significa também reduzir a capacidade de aprendizagem dos alunos. Eles perderam anos de suas vidas quando, por negligência, foram deixados a sua própria condução, o que os levou a trágica situação em que se encontram, são internos e continuam tendo sua educação deixada a sua própria condução.

Muitos professores ficam com pena dos/as adolescentes que já sofreram tanto e transformam a sala de aula num espaço prioritariamente lúdico, de uma forma ainda mais radical que na educação pública em geral. Os alunos precisam aprender a ser conduzidos para a apropriação do conhecimento, esse é grande o desafio da educação escolar para adolescentes que cumprem medidas socioeducativas de internação em estabelecimento educacional.

Desde bebê a criança vai internalizando formas de controle social. Uma mãe evita dar o seio a ele, de madrugada, para que ele deixe de mamar naquele horário e ela possa dormir e descansar durante a noite. Nos primeiros 
dias o bebê sofre e chora, mas se a mãe for persistente em alguns dias o bebê irá desenvolver o hábito de dormir a noite toda e sua mãe poderá descansar. O sofrimento do bebê naquele curto espaço de tempo foi necessário, caso contrário a mãe não conseguiria descansar e isso poderia prejudicar ambos. Existem mães que têm dificuldade em colocar limites nos filhos e isso pode afetar negativamente o desenvolvimento e a educação deles.

A escola é, sem dúvida, o mais importante meio de ressarcir o direito dos/as adolescentes que não aprenderam a respeitar a autoridade e não têm controle sobre a própria conduta. Mais do que a grande maioria da sociedade, os adolescentes em privação de liberdade precisam e podem receber uma educação escolar diretiva e disciplinadora que possibilite a efetiva apropriação dos códigos das linguagens mais complexas para serem por eles utilizados como ferramentas da conquista de sua própria cidadania. A ausência de uma educação eficaz é uma forma de negligência, como aponta o artigo $5^{\circ}$ do Estatuto da Criança e do Adolescente, que não poderia acontecer durante o cumprimento da medida socioeducativa de internação.

\section{EDUCATION OF INCARCERATED ADOLESCENTS: A VYGOTSKYAN APPROACH}

ABSTRACT: Teenagers who are under socio-educational measure of internment have a record of extremely low school attendance, before, during, and after the period of incarceration. Based on the Historical and Cultural Psychology of L.S. Vygotsky, this article provides the foundation for a notion that the psychism is historical and not innate, nor an ideal of the spirit, assuming a greater appreciation of science content in the education of these youngsters. In the third part, it offers a basis for criticism regarding the pedagogical practice that exceedingly values the entertainment and views the authority and discipline as authoritative and ineffective pedagogic procedures. It concludes that the concentration and the discipline for the appropriation of the so-called classic knowledge are fundamental to the development of incarcerated adolescents.

KEYWORDs: Adolescents. Socio-educational measures. Education. Teaching. 


\section{EDUCACIÓN DE ADOLESCENTES PRIVADOS DE LIBERTAD: UN ABORDAJE VYGOTSKIANO}

RESUMEN: Los adolescentes que cumplen medida socioeducativa de internación tienen un histórico de bajísima frecuencia escolar, antes, durante y después de la internación. Utilizando la psicología Histórico-Cultural de L. S. Vygotski, el artículo fundamenta la concepción de que el psiquismo es histórico y no innato o un ideal del espíritu, presuponiendo una mayor valoración de contenidos científicos en la educación escolar de esos adolescentes. En su tercera parte fundamenta una crítica a la práctica pedagógica que valora excesivamente lo lúdico y que entiende la autoridad y la disciplina como procedimientos pedagógicos autoritarios e ineficaces. Concluye que la concentración y la disciplina para la apropiación de conocimientos dichos clásicos son fundamentales para el desarrollo de los adolescentes privados de libertad.

Palabras clave: Adolescente. Medida socioeducativa. Educación; Enseñanza.

\section{NOTAS}

1) $O$ conceito de Fenomenologia aqui utilizado tem o mesmo sentido dado por Vygotski (2004) quando o autor faz a crítica desse pressuposto teórico e metodológico, pelo aspecto fragmentado, idealista e não histórico.

2) Referimo-nos à pesquisa realizada em regiões remotas da URSS por Alexander Lúria e outros pesquisadores, em 1931 e 1932, sobre a transição de um modo de pensamento primitivo para um modo mais teórico e abstrato induzidos pelas políticas públicas soviéticas (LURIA, 1991 e VYGOTSKY e LURIA, 1996).

3) $\mathrm{O}$ texto respeita as grafias conforme as traduções. Nas traduções diretamente do russo para o português escreve-se "Vigotski"; nas traduções do espanhol para o português escreve-se "Vygotski"; e nas traduções do inglês para o português escreve-se "Vygotsky", conforme observado nas referências bibliográficas.

4) Vários autores e grupos de pesquisa em educação vêm fazendo a crítica à tendência, hegemônica hoje no Brasil, que concebe o senso comum e o lúdico como centrais na educação escolar (MARTINS, 2007 e 2012; FACCI, 2004; ARCE, 2002; DUARTE, 1999, 2000 e 2001). 


\section{REFERÊNCIAS}

SINASE. Base de dados do Sistema Socioeducativo. Brasília, SDH-PR: 2012.

ARCE, A. A pedagogia na "era das revoluções": uma análise do pensamento de Pestalozzi e Froebel. Campinas: Autores Associados, 2002.

DUARTE, N. Vigotski e o "aprender a aprender": crítica às apropriações neoliberais e pós- modernas da teoria vigotskiana. Campinas: Autores Associados, 2001.

. A anatomia do homem é a chave para a anatomia do macaco: a dialética em Vigotski e em Marx e a questão do saber objetivo na educação escolar. Educação e Sociedade, São Paulo, ano 21, n. 71, p. 79-115, jul. 2000.

Educação escolar, teoria do cotidiano e a escola de Vigotski. Campinas: Editores Associados, 1999.

FACCI, M. G. D. Valorização ou esvaziamento do trabalho do professor? Um estudo crítico-comparativo da teoria do professor reflexivo, do construtivismo e da psicologia vigotskiana. Campinas: Autores Associados, 2004.

LEONTIEV, A. N. O desenvolvimento do psiquismo. Lisboa: Horizonte, 1978.

LURIA, A. R. Curso de psicología geral. v. 1. Rio de Janeiro: Civilização Brasileira, 1991. MARTINS, L. M.; ARCE, A. Quem tem medo de ensinar na educação infantil: em defesa do ato de ensinar. Campinas: Alínea, 2007.

. A formação social da personalidade do professor: um enfoque vigotskiano. Campinas: Autores Associados, 2007.

. O desenvolvimento do Psiquismo e a educação escolar: contribuições a luz da psicologia histórico-cultural e da Pedagogia Histórico-Crítica. Interface, Botucatu, v. 16, n. 40, p. 283, jan./mai. 2012.

SAVIANI, D. Pedagogia histórico-crítica. Campinas: Autores Associados, 2003.

. Escola e democracia. Campinas: Autores Associados, 1995.

VIGOTSKI. L. S. Psicologia Pedagógica. São Paulo: Martins Fontes, 2001 a. $2001 \mathrm{~b}$.

A construção do pensamento e da linguagem. São Paulo: Martins Fontes, _. Teoria e método em psicologia. São Paulo. Martins Fontes: Martins Fontes, 2004.

. Obras escorridas - Volumes III. Madri: Centro de Publicaciones del M.E.C.; Visor Distribuciones, 1995.

; LURIA, A. R. Estudos sobre a história do comportamento: o macaco, o primitivo e a criança. Porto Alegre: Artes Médicas, 1996. 
Paulo Cesar Duarte Paes: Doutor em Educação pela Universidade Federal de São Carlos. É professor adjunto da Universidade Federal de Mato Grosso do Sul (artes visuais e psicologia do desenvolvimento e da aprendizagem). Assessor da Secretaria nacional de Direitos Humanos da Presidência da República, Coordenação Nacional do SINASE. Tem experiência na área de Educação, atuando principalmente nas seguintes áreas: ensino de artes visuais; socioeducação; redução de danos, direitos da criança e do adolescente e psicologia do desenvolvimento e da aprendizagem com foco em Vigotski.

E-mail: pdpaes@yahoo.com.br 